\title{
Biossegurança e sistemas de informação: a rede e o gerenciamento de risco
}

\section{Biosafety and information systems: the network and risk assessment}

\author{
José Pereira Ardións ${ }^{1}$, Marli Brito Moreira de Albuquerque Navarro², \\ Telma Abdalla de Oliveira Cardoso ${ }^{3}$
}

\begin{abstract}
Resumo
Este trabalho contextualiza a inserção da internet na sociedade contemporânea a partir da discussão sobre a construção da sociedade de risco, enfatizando as possibilidades dessa ferramenta para processar de forma ágil gerenciamentos de contextos de risco, considerando a ampla rede de interlocutores que podem ser notificados para organizar estratégias e ações imediatas diante de eventos que caracterizam a projeção do risco em largo alcance. Tem como objetivo analisar a importância da construção de solidariedades cognitivas e práticas entre a Ciência da Informação e o campo da Biossegurança para favorecer estratégias e instrumentos de monitoramento de risco por meio da organização de informações em termos de relevâncias quantitativos e qualitativos.
\end{abstract}

Palavras-chave: controle de risco; exposição a agentes biológicos; sistemas de informação.

\begin{abstract}
The present paper points out internet's role within modern society, regarding the debate on the building of a society of risk. The wide possibilities of this tool as a processor for management and risk assessment and the importance of building a cognitive solidarization practice between the disciplines of Biosafety and Science Information have been addressed. Risk assessment shall also be carried out, whether by the organization of information or through quantitative and qualitative data.
\end{abstract}

Keywords: risk management; exposure to biological agents; information systems.

Trabalho realizado no Núcleo de Biossegurança do Departamento de Saneamento e Saúde Ambiental da Escola Nacional de Saúde Pública (ENSP) da Fundação Oswaldo Cruz (FIOCRUZ) - Rio de Janeiro (RJ), Brasil.

'Especialista em Tecnologia da Informação; Tecnologista sênior do Núcleo de Biossegurança do Departamento de Saneamento e Saúde Ambiental da ENSP/ FIOCRUZ - Rio de Janeiro (RJ), Brasil.

²Doutora em História Contemporânea pela Université Paris X; Pesquisadora sênior do Núcleo de Biossegurança do Departamento de Saneamento e Saúde Ambiental da ENSP/FIOCRUZ - Rio de Janeiro (RJ), Brasil.

${ }^{3}$ Pós-doutoranda em Medicina Legal da Universidade de Coimbra, Portugal; Pesquisadora sênior do Núcleo de Biossegurança do Departamento de Saneamento e Saúde Ambiental da ENSP/FIOCRUZ - Rio de Janeiro (RJ), Brasil.

Endereço para correspondência: José Pereira Ardions - Avenida Brasil, 4036, sala 175/716 - CEP: 21040-361 - Rio de Janeiro (RJ), Brasil - E-mail:

ardions@fiocruz.br

Conflito de interesses: nada a declarar. 


\section{INTRODUÇÃO}

O campo da Biossegurança está inserido como componente relevante na caracterização da "sociedade de risco", que considera os processos sugestivos de vulnerabilidades e incertezas como elementos que devem compor as análises que precedem a elaboração de decisões, valorizando a compreensão dos contextos que traduzem apreensões, dúvidas, tensões e medos de âmbito global, que atingem os indivíduos, os governos e as instituições.

Uma das características da sociedade de risco é a revisão continua dos contextos que indicam instabilidades e vulnerabilidades. Para tanto, conta com novas informações ou conhecimentos, já que a natureza dos riscos muda continuamente e muitas vezes eles passam a ser mais complexos, produtos do desenvolvimento da ciência e da tecnologia, numa tendência à desterritorialização e à globalização ${ }^{1}$, caracterizada pela predominância da forma organizacional da rede em todos os campos da vida social ${ }^{2}$.

Pensadores dos fenômenos transformadores da modernidade clássica, tais como Manuel Castells, por meio da análise da Sociedade em Rede, Anthony Giddens e Ulrich Beck, que desenvolveram análises formuladoras da proposição sociológica situada na complexidade da globalização, da revolução da tecnologia da informação e da construção de uma sociedade mundial do risco, associada à ideia da modernidade reflexiva; situam os elementos - informação, risco, reflexão - como integradores fundamentais da atual identidade das sociedades contemporâneas.

Tanto para Giddens ${ }^{3}$ quanto para Lévy ${ }^{4}$, a reflexão favorecida pelas informações obtidas na rede de comunicação propicia a rápida circulação sobre os riscos presentes nas mais diversas partes do mundo, transformando e modificando a maioria das capacidades cognitivas, redefinindo as relações de conhecimento.

Entre as questões que refletem dúvidas e apreensões da sociedade estão as estabelecidas pelos processos científicos e tecnológicos, que provocam constantemente motivações reflexivas sobre os benefícios e os riscos do mundo contemporâneo e sua relação com tais processos.

Várias dimensões do risco transitam cotidianamente na vida pessoal e coletiva dos indivíduos, estando, pois, as percepções de riscos permeadas pela perspectiva pessoal e pela perspectiva coletiva. As questões objetivas e subjetivas advindas das discussões sobre elementos formuladores da "sociedade de risco" saíram dos limites dos debates formulados e alimentados pela comunidade científica e chegaram ao cotidiano social, por meio, sobretudo, da expansão da informação e de suas ferramentas de alcance global.

Destaca-se também que a relação entre informação e veiculação imediata dos riscos de dimensões coletivas está presente nas proposições que visam subsidiar políticas globais. Segundo a Organização para a Cooperação e Desenvolvimento Econômico ${ }^{5}$,

[...] não somente a natureza dos riscos maiores parece estar mudando, mas também o contexto no qual estes aparecem, e a capacidade da sociedade em gerenciá-los. As forças que provocam estas mudanças são muitas e diversas. Por exemplo, as condições climáticas aparecem como sendo cada vez mais extremas. A densidade populacional nos centros urbanos e a concentração da atividade econômica em certas regiões estão aumentando, tornando estas áreas mais vulneráveis. A globalização sob todos os aspectos econômico, tecnológico, cultural, ambiental - está crescendo rapidamente e ampliando a interdependência, de tal modo que vírus perigosos, poluentes e falhas técnicas tenham mais facilidade em se espalharem. De igual importância, as fronteiras da descoberta científica e da inovação tecnológica estão conhecendo expansão excepcionalmente rápida, a sociedade sendo assim confrontada com efeitos desconhecidos (e difíceis de conhecer), e, por conseguinte com escolhas extremamente difíceis. (p. 3)

A OCDE vem construindo bases analíticas sobre os contextos dos riscos emergentes e sistêmicos que ocorrem com frequência na atualidade, para subsidiar proposições referentes à necessidade de definição de políticas para o equacionamento de tais contextos, como a formulação de estratégias de gestão de risco em níveis globais.

\section{BIOSSEGURANÇA E INFORMAÇÃO: EQUACIONANDO TECNOLOGIA E RISCO}

A sociedade industrial, em especial, no século XX, registrou um profundo estreitamento da relação entre ciência e técnica, favorecendo mudanças sociais significativas, contribuindo, entre outras possibilidades, para a popularização e o aumento de produtos, cujo valor centralizou-se no teor tecnológico como sinônimo de qualidade (utensílios, serviços, métodos etc.). Esta popularização contribuiu igualmente para a formulação de um imaginário social ancorado nas projeções de perspectivas positivas advindas das comodidades e das respostas tecnológicas para as preocupações humanas.

O efeito trágico e emblemático do uso bélico da tecnologia nuclear, por exemplo, que resultou na destruição de Hiroshima e Nagasaki, colocou em pauta, sobretudo para a sociedade, a relatividade das "promessas" otimistas vinculadas aos avanços da tecnologia como benefício para a humanidade, despertando igualmente para a identificação da relação entre 
ciência, tecnologia e risco. Cortez ${ }^{6}$ resgatou a importância do manejo e aplicação da energia nuclear para as análises de risco, em especial, os que são advindos dessa tecnologia. Em tal resgate, $\mathrm{o}$ autor destacou o vazamento de radioatividade na usina russa de Tcheliabinski, em setembro de 1957, onde houve a contaminação de 270 mil pessoas. Em dezembro desse mesmo ano, na antiga União Soviética houve o superaquecimento de um tanque de depósito de resíduos nucleares, causando uma explosão e liberação de compostos radioativos numa área de $23 \mathrm{mil} \mathrm{km}^{2}$. Mais de 30 pequenas comunidades, numa área de $1.200 \mathrm{~km}^{2}$, foram evacuadas com o deslocamento de 17.200 pessoas. Em 1992, um relatório informava que 8.015 pessoas já haviam morrido em decorrência dos efeitos desse acidente.

Nos Estados Unidos, também há muitos registros desse tipo de acidente. $\mathrm{O}$ acidente de maior impacto foi o ocorrido em 28 de março de 1979, na Usina de Three Mile Island, na Pensilvânia. Uma falha na refrigeração de um dos reatores da Usina levou ao derretimento do seu núcleo. Os rejeitos radioativos contaminaram o interior do recinto de confinamento, destruindo $70 \%$ do núcleo do reator. Cerca de 140 mil moradores próximos foram evacuados ${ }^{6}$.

Outro acidente de grande repercussão ocorreu em 26 de abril de 1986, na usina nuclear soviética de Chernobyl na Ucrânia (então parte da União Soviética). Um dos quatro reatores da usina explodiu, lançando na atmosfera uma nuvem radioativa de cem milhões de curies (nível de radiação 6 milhões de vezes maior do que o nível de radiação da usina de Three Mile Island), atingindo a União Soviética, Europa Oriental, Escandinávia e Reino Unido. Metade das substâncias radioativas voláteis que existiam no núcleo do reator foi lançada na atmosfera (principalmente iodo e césio). A Ucrânia, a Bielorússia e o oeste da Rússia foram regiões atingidas por uma precipitação radioativa de mais de 50 toneladas, o que resultou na evacuação e reassentamento de aproximadamente 200 mil pessoas $^{6}$.

No Brasil, um dos relatos mais impactantes referiu-se ao acidente em Goiânia, ocorrido em 13 de setembro de 1987, envolvendo o Césio-137. Um aparelho utilizado em radioterapia de um hospital abandonado foi encontrado por catadores de um ferro velho do local, que entenderam tratar-se de sucata. Foi desmontado e repassado para terceiros, gerando um rastro de contaminação e expondo aproximadamente $200 \mathrm{mil}$ pessoas aos efeitos do Césio ${ }^{7}$.

Em termos globais, os riscos relacionados direta ou indiretamente ao uso da tecnologia nuclear estão na pauta de preocupação dos governos, das empresas e das sociedades. Também os acidentes com usinas nucleares, associados aos eventos naturais de grande impacto (terremotos e tsunamis, por exemplo) revelaram, recentemente, no Japão uma forte manifestação social contrária ao uso, mesmo que pacífico dessa tecnologia.

Outro contexto que gera importante apreensão social, motivando também debates quanto aos riscos e benefícios científicos, econômicos, políticos e sociais está situado na utilização comercial em larga escala da biotecnologia baseada na recombinação genética voltada para o agronegócio.

Na década de 1970, a ampliação das possibilidades da biotecnologia, por meio da aplicação da tecnologia do DNA/RNA recombinante, projetou para a sociedade e para a própria comunidade científica questões relativas ao incentivo e ao avanço da ciência e da tecnologia, admitindo campos de incertezas, considerando também a complexidade dos contextos vinculados ao poder econômico, à saúde humana e à saúde ambiental, colocando como questão privilegiada a segurança dos laboratórios, além dos dilemas éticos e morais, entre outras - debates que resultaram na formulação da Biossegurança como campo destinado a propor meios para o controle e o monitoramento dos riscos advindos do "fazer científico".

Atualmente, observa-se que a problemática do risco permite a estruturação de críticas à ciência e à tecnologia que alcançam várias áreas de aplicação do conhecimento científico, tais como Medicina, Biologia e Física, abrangendo também a Ciência da Informação, as Ciências Políticas, Econômicas e Sociais, ou seja, áreas nas quais os conceitos de incerteza e contingência devem ser privilegiados como componentes cognitivos da pesquisa e da aplicabilidade, exigindo, pois, ações sistemáticas de análise e monitoramento de risco.

As décadas de 1970 e 1980 são consideradas como "avant-guarde" nas análises de risco relativo dos processos tecnológicos de grande impacto, quando representantes da academia identificados com as teorias revisionistas do pensamento cartesiano destacaram-se. Esse movimento cognitivo dirigiu-se para reflexões sobre o imperativo do risco na contemporaneidade a partir das conjunturas demonstrativas de imprevisibilidades de situações e contextos vinculados, sobretudo, ao desenvolvimento técnico-industrial, enfatizando-se a dinâmica global da busca de informações sobre processos, contextos, produtos e situações de risco (risco ambiental, risco de consumo, risco de tecnologias etc.), criando um movimento recíproco entre busca e estruturação de informações no campo da Biossegurança.

As discussões sobre risco, que antes ficavam quase exclusivamente restritas às dimensões teóricas e conceituais, circulando com maior ênfase no âmbito da comunidade científica, no começo do século XXI passaram a ocupar um espaço considerável na mídia. O risco como componente da dinâmica da sociedade penetrou no cotidiano dos indivíduos de forma importante: desastres naturais, bioterrorismo, aquecimento 
global, pandemias, emergência de novas doenças, ressurgência de doenças tidas como controladas, alimentos obtidos por Engenheira Genética, são exemplos de questões que transpuseram a linha da probabilidade remota do dano humano e/ou ambiental, individual ou coletivo, local ou global.

As conquistas científicas e tecnológicas realizadas não foram capazes de garantir as promessas de segurança e de conforto que a sociedade ansiava, colocando tanto para os especialistas como para os leigos preocupações pertinentes às ações e procedimentos minimizadores e controladores dos riscos. Esses fatores determinaram a ampliação da demanda informacional sobre o campo da Biossegurança e de temáticas de sua abrangência, tais como precaução, jurisprudência, bioética, preservação ambiental e saúde pública.

Considerando a perspectiva de privilegiar a importância dos mais diversos enfoques relacionados aos riscos à saúde humana e ambiental; o campo da Biossegurança foi conceituado como

um conjunto de saberes direcionados para ações de prevenção, minimização ou eliminação de riscos inerentes às atividades que possam comprometer a saúde do homem, dos animais, das plantas e do meio ambiente ou a qualidade dos trabalhos desenvolvidos ${ }^{8}$. (p. 88)

Como o indivíduo é um ser reflexivo, que quando confrontado com suas próprias ações reflete e estabelece críticas racionais sobre si, das consequências de fatos passados às condições atuais e da probabilidade de possíveis riscos futuros ${ }^{9}$, a Biossegurança deve considerar a subjetividade das percepções, uma vez que as construções e os controles dos riscos pertencem aos contínuos e dinâmicos processos de inovação e (re) construção de conhecimentos. Nesse sentido, as tecnologias de informação - entre estas, os sistemas para acesso, busca, tratamento, utilização e disseminação de informações - funcionam como um mecanismo de suporte capaz de auxiliar e dinamizar a produção de conhecimentos e compreensões de processos formuladores de eventos potencialmente perigosos em dimensões globais (exemplo da gripe aviária e a possibilidade de uma pandemia) e mesmo a viabilidade de impactos desconhecidos (possibilidade da mutação de vírus).

\section{TECNOLOGIA DA INFORMAÇÃO PARA A GESTÃO DO CONHECIMENTO}

As tecnologias da informação trouxeram modificações às relações da informação com seus usuários. Na cultura escrita, a informação é fragmentada, individualista, contínua e especializada. A revolução tecnológica alterou radicalmente a delimitação de tempo e espaço, permitindo novas formas de estruturação e funcionamento da economia, de organização da produção e do acesso ao conhecimento ${ }^{10}$. A sociedade que se delimita a partir de então passa a ser caracterizada por diversas terminologias, como "Sociedade do Conhecimento"11, "Sociedade Digital"12, "Sociedade da Aprendizagem"13, "Sociedade em Rede", "Sociedade da Informação"14 e "Era da Informação"15. Nessa sociedade, o conhecimento científico é estruturante para a expansão econômica no mundo contemporâneo, e a partir do qual se desenvolve a capacidade de inovação tecnológica ${ }^{16}$. Esse movimento gera consequências técnicas, sociais, culturais, políticas e econômicas cumulativas e irreversíveis e, consequentemente, modifica as formas de discutir e organizar a sociedade ${ }^{17,18}$. A informação é o elemento mais utilizado para a vida econômica, social, cultural e política.

Castells $^{2}$ aponta que a sociedade ocidental é caracterizada pela

globalização das atividades econômicas; por sua forma de organização em redes; pela flexibilidade e instabilidade no emprego e a individualização da mão-de-obra. Por uma cultura de virtualidade real construída a partir de um sistema de mídia onipresente, interligado e altamente diversificado. E pela transformação das bases materiais da vida - o tempo e o espaço - mediante a criação de um espaço de fluxos e de um tempo intemporal [...] (p. 17)

A tecnologia tornou-se parte integrante do processo de pesquisa e da produção do conhecimento e é uma ferramenta intelectual que possibilita o desenvolvimento de redes de inteligência coletiva ${ }^{4}$, em um ciclo regenerativo e interativo. Nesse contexto, temos como vetor a interatividade que gera novas informações, abrindo janelas por meio das quais se criam novas chances para o estabelecimento de trocas cognitivas que contribuem para a formulação crítica do conhecimento, auxiliando o avanço do pensar, do decidir e do produzir. Assim, a informação é, sobretudo, um processo, e não apenas um elemento. Ela favorece a ampliação do potencial reflexivo dos indivíduos e dos grupos, estimulando contextos cooperativos para a construção da diversidade, da complexidade e da qualidade da informação, diminuindo o "risco" da linearidade cognitiva ${ }^{19}$.

Um grande número de agentes cognitivos humanos pode interligar-se em um mesmo processo de construção de conhecimentos. E os próprios sistemas interagentes artificiais se transformaram em máquinas cooperativas, com as quais podemos estabelecer parcerias na pesquisa e no aviamento de experiências de aprendizagem ${ }^{19}$. (p. 9) 
Como parte do processo da relação informação/conhecimento/decisão, pode-se contar com diversas tecnologias e canais, formais e informais, para comunicação da informação e construção crítica do conhecimento. Entre essas tecnologias, a internet oferece condições para um tipo de comunicação que se destaca pela agilidade, rapidez e alcance global da informação. Observa-se, no entanto, a importância da percepção crítica das informações veiculadas por esse meio.

Os recursos possibilitados pela rede favorecem as inovações das Tecnologias de Informação e Comunicação (TIC), que podem ser utilizadas para subsidiar mecanismos metodológicos, ancoradas nas possibilidades dos espaços virtuais para promoção integrada da informação, da educação e do aprendizado, visando à produção do conhecimento, modificando o estoque mental do indivíduo e beneficiando o seu desenvolvimento e o desenvolvimento da sociedade onde ele vive ${ }^{20}$.

Os sistemas de informação baseados na tecnologia web envolvem recursos de hipermídia, arquitetura de comunicação capaz de suportar grande número de acessos, questões de segurança e interligação com os sistemas existentes, executados na internet, e criam uma rede de alcance mundial. Eles oferecem um ambiente virtual com informações vinculadas com variadas interconexões.

\section{A IMPORTÂNCIA DA REDE NA COMUNICAÇÃO DE RISCO: INFORMAÇÃO E BIOSSEGURANÇA.}

As atividades de comunicação ocupam lugar de destaque em todas as etapas dos processos de administração de crises ou de gerenciamento de riscos. A comunicação de risco é um processo interativo de troca de informação e de opiniões entre pessoas, grupos e instituições. É um diálogo no qual são discutidas múltiplas mensagens que expressam preocupações, opiniões ou reações às próprias mensagens ou arranjos legais e institucionais da gestão ou do gerenciamento de riscos ${ }^{21}$. É utilizada como ferramenta de orientação e de divulgação das ações de levantamento de informações para a análise do risco; possui também um papel essencial para a criação ou ampliação do conhecimento e, assim, corrobora para a amplificação da percepção de risco. Porém, ressalta-se que a percepção está integrada a um contexto coletivo que abrange a perspectiva comportamental, associada também aos fatores pessoais relacionados à capacidade da formulação cognitiva, aos aspectos afetivos e biológicos e as possibilidades de leitura e de interação com o ambiente externo ${ }^{22}$.

No mundo contemporâneo o fenômeno da globalização é traduzido também pela complexidade dos riscos, destacandose o risco à saúde pública e ao ambiente. Essa realidade faz com que o campo de conhecimento da Biossegurança avance no sentido de ampliar suas ações a fim de elaborar procedimentos eficazes no enfrentamento da complexidade dos contextos de risco, destacando-se o risco biológico, expressos nas doenças emergentes e reemergentes, no bioterrorismo, na predação ambiental, no comprometimento do patrimônio ecológico do planeta e de seu equilíbrio. Esses aspectos estão associados aos processos de circulação de pessoas e de produtos, relevante fluxo migratório, pobreza, guerras, rapidez dos transportes, entre outros, configurando um contexto que coloca importantes e complexos desafios para a saúde pública, observando, assim, o imperativo do gerenciamento de risco, sobretudo, em termos globais.

Nessa perspectiva, Peres ${ }^{23}$ destaca que

a comunicação de riscos precisa, inicialmente, tornar real o problema, sensibilizando cada ator envolvido da importância de se adotarem medidas visando a garantia da saúde, do bem-estar de todos e do ambiente (p. 296).

Assim, poder-se-á avaliar, com clareza, o papel de qualquer tecnologia, processo ou agente e ponderar sobre seus riscos e seus benefícios, para si, para a sociedade ou para o ambiente.

\section{CONSIDERAÇÕES FINAIS}

Os indivíduos, as organizações públicas e privadas e os governos vêm tendo cada vez mais acesso aos recursos oferecidos pela internet, acelerando o fluxo da informação em todo o mundo - questões que envolvam aspectos de risco de qualquer ordem e natureza podem ser divulgadas, discutidas e monitoradas de forma global, no instante que o evento venha a ocorrer.

Em decorrência desse novo cenário, a internet se transforma numa importante ferramenta para alertar situações de risco, alcançando uma ampla rede de interlocutores que podem ser notificados para organizar estratégias e ações para essas ocorrências. Os recursos tecnológicos que envolvem servidores de páginas web, gerenciador de banco de dados e aplicações desenvolvidas para dar suporte a situações de risco oferecem um ambiente conciso e dinâmico no qual o usuário terá acesso a uma base de conhecimento e a interlocução em tempo real com seus parceiros.

Governos passam a utilizar essa rede mundial definindo "estados de alerta", que no exemplo da Defesa Civil é dividido em estados de observação, atenção, alerta e alerta máximo, dividindo seus interlocutores em dois grupos, os "operadores do sistema", que são as organizações que monitoram a possibilidade de ocorrência de desastres naturais, e os "clientes dos alertas", ou agentes que executam as ações preventivas para a diminuição de perdas no caso da ocorrência de um desastre. 
Esses indivíduos são responsáveis por alimentar as bases de dados que apoiam as ações de intervenção e solução das situações de risco alarmadas.

Assim, é fundamental refletir sobre os níveis de potencialização das tecnologias de comunicação e de informação, em especial a internet, como instrumento constitutivo do processo de formulação e divulgação do conhecimento nos dias atuais, instrumento que se estabelece também como promotor do fluxo das trocas cognitivas na comunicação científica, ganhando a denominação de comunicação eletrônica, caracterizada especialmente pela agilidade e favorecimento de cruzamentos de conteúdos, pois, é fato, o acesso aberto às publicações científicas, por intermédio de download, cópias, impressões, distribuições, buscas, relação de links, como meio de ampliação das informações e das possibilidades de leituras críticas como matriz geradora de novos conhecimentos, é uma dinâmica que contempla direta e/ou indiretamente o diálogo entre cientistas, pensadores, especialistas, estudiosos e profissionais no sentido da formulação de solidariedades entre conhecimentos e a difusão qualificada dos mesmos.

\section{REFERÊNCIAS}

1. Luiz OC, Cohn A. Sociedade de risco e risco epidemiológico. Cad Saúde Pública. 2006;22(11):2339-48.

2. Castells M. A era da informação: economia, sociedade e cultura. A sociedade em rede. v.1. São Paulo: Paz e Terra; 1999.

3. Giddens A. A vida em uma sociedade pós-industrial. In: Beck U, Giddens A, Lash S. (Orgs.). Modernização reflexiva: política, tradição e estética na ordem social moderna. São Paulo: Editora da Universidade Estadual Paulista; 1995. p. 73-133.

4. Lévy P. A inteligência coletiva: por uma antropologia do ciberespaço. 3. ed. São Paulo: Loyola; 2000.

5. Organisation for Economic Co-operation and Development. OCDE. Overview Emerging Risks in the 21Century: an Agenda for Action. Síntese Riscos Emergentes no Século XXI: Programa de Ação. OCDE, 2003. [cited 2012 Oct 30] Available from: http://www.oecd. org/bookshop/

6. Cortez H. Aquecimento Global e Água. Série: Consciência e Meio Ambiente. São Paulo: Câmara de Cultura; 2004. 94p. [cited 2012 Oct 12] Available from: http://www.camaradecultura.org/livro-f.pdf

7. Hellou S, Costa Neto SB. (Orgs). Césio-137: consequências psicossociais do acidente de Goiânia. Goiânia: UFG; 1995.

8. Ministério da Saúde. Fundação Oswaldo Cruz. Núcleo de Biossegurança. Relatório sobre as Condições de Biossegurança Face aos Riscos Biológicos Referidos por Quatro Instituições de Pesquisa em Saúde no Brasil. In: Marques MB (Org.) Por uma Política de Ciência e Tecnologia em Saúde no Brasil. Rio de Janeiro: Fundação Oswaldo Cruz; 1995. p. 87-102.

9. Beck U, Giddens A, Lash S. Modernização Reflexiva: política, tradição e estética na ordem social moderna. São Paulo: UNESP; 1995.

10. Castells M. A Galáxia Internet: reflexões sobre a Internet, negócios e a sociedade. Lisboa: Fundação Calouste Gulbenkien; 2004.

11. Drucker P. Administração de organizações sem fins lucrativos: princípios e práticas. São Paulo: Pioneira Thomson Learning; 1994.
12. Negroponte N. A vida digital. 2 ed. São Paulo: Companhia das Letras; 1995.

13. Lévy P. Cibercultura. São Paulo: Editora 34; 1999.

14. Takahashi T. Sociedade da informação no Brasil: livro verde. Brasília: Ministério da Ciência e Tecnologia; 2000.

15. Castells M. O poder da identidade. A era da informação: economia, sociedade e cultura. vol. 2. 2 ed. São Paulo: Paz e Terra; 2000.

16. Sorj B. Brasil@povo.com: a luta contra a desigualdade na sociedade da informação. Rio de Janeiro; Brasília: Jorge Zahar; UNESCO, 2003.

17. Silva AKA, Correia AEGC, Lima IF. O Conhecimento e as Tecnologias na Sociedade da Informação. Rev Interam Bibliot Medellín (Colombia). 2010;33(1):213-39.

18. Barbosa DCM, Forster AC. Sistemas de Informação em Saúde: a perspectiva e a avaliação dos profissionais envolvidos na Atenção Básica à Saúde de Ribeirão Preto, São Paulo. Cad Saúde Colet. 2010;18(3):424-33.

19. Assmann H. A metamorfose do aprender na sociedade da informação. Ciência da Informação. 2000;29(2):7-15.

20. Barreto AA. A questão da informação. SP em Perspectiva. 1994;8(4). [cited 2013 Jan 12] Available from: http://aldoibct.bighost.com.br/quest/ quest2.pdf

21. National Research Council. Improving Risk Communication. Washington: National Academy Press; 1989.

22. Navarro MBMA, Cardoso TAO. Percepção e risco e cognição: reflexão sobre a sociedade de risco. Ciências \& Cognição. 2005;6(1):67-72.

23. Peres F. Biossegurança, saúde, ambiente e comunicação de riscos: um debate necessário. Ciênc Saúde Coletiva. 2012;17(2):294-7.

Recebido em: 16/07/2013 Aprovado em: 02/09/2013 